\title{
MANAGEMENT OF POST-PARTUM UTERINE PROLAPSE IN A GOAT WITH VULVAL LIP SUTURE TECHNIQUE
}

\author{
K. P. SINGH*, B. SINGH ${ }^{1}$, R.V. SINGH ${ }^{2}$ \\ P. SINGH ${ }^{3}$ AND S. K. SINGH \\ Government Veterinary Hospital \\ Department of Animal Husbandry \\ Deoranian, Bareilly,Uttar Pradesh-243 203, India
}

\begin{abstract}
The present study was conducted for management of post-partum uterine prolapse in a non-descript goat of $25 \mathrm{Kg}$ body weight with vulval lip suture technique. A two years old goat of $2^{\text {nd }}$ pregnancy was presented with history of uterine prolapse following normal kidding of 2 kids 48 hours earlier. The prolapsed uterus was injured, swollen, edematous and contaminated with dung and wheat straw. The prolapsed mass was lacerated and had numerous bleeding points. Vaginal wall was edematous, swollen, thicker and bluish pink in appearance. The epidural anesthesia was achieved by giving $2 \%$ lignocaine hydrochloride @ $4 \mathrm{mg} / \mathrm{Kg}$ body weight into lumbosacral space to prevent straining during replacement of prolapsed mass. The prolapsed mass was washed with chilled water containing potasium permagnate (1: 1000) followed by flushing with metronidazole solution. The prolapsed mass was lubricated with xylocain gel and replaced into normal position by gentle pressure. The body of the uterus was first pushed forward followed by horns. Buhner suture using nylon (size 0) was placed in the vulva as a retention technique to hold the uterus in place. The animal was treated with injection calcium magnesium borogluconate @ $1 \mathrm{~mL} / \mathrm{Kg}$ body weight, $5 \%$ dextrose normal saline (DNS), oxytocin. ceftriaxone, meloxicam, chlorphenramine maleate and $B_{1,} B_{6}$ and $B_{12}$. The owner was also advised to apply antimicrobial ointment on suture line for preventing infection. The animal showed recovery after 3 days and further no prolapse was reported by the owner. The Buhner suture was removed after $\mathbf{7}$ days post management.
\end{abstract}

Key words: Epidural anesthesia, Prolapsed mass, Reduction, Reposition, Retention

Post-partum uterine prolapse occurs in all species of domesticated animals. It is most common in cows and ewe, less common in the doe goat and rare in the mare. It is an eversion of the uterus which turns inside out as it passes through the vagina. Prolapse

\footnotetext{
*Corresponding Author

${ }^{1}$ Deparment of Animal Reproduction, Gynaecology and Obstetrics, C.V.Sc. \& A.H., NDUAT, Kumarganj, Faizabad, U.P

${ }^{2}$ Department of Pharmacology, Bhavdiya Institute of Pharmaceutical Sciences and Research, Faizabad, U.P. ${ }^{3}$ Department of Livestock Product Technology, C.V.A.Sc., GBPUAT, Pantnagar, U.S.Nagar, Uttrakhand ${ }^{4}$ Government Veterinary Hosptal, Ailiya, Sitapur, Uttar Pradesh
} 
of uterus generally occurs immediately after or few hours of parturition when the cervix is open and the uterus has lacks of tone (Hanie, 2006). Prolapse that occurs more than 24 hours post-partum is extremely rare and is complicated by partial closure of cervix making replacement difficult or even impossible (Fubini and Ducharme, 2006). The prolapse is visible as a large mass protruding from the vulva, often hanging down below the animal's hock. It normally occurs during the third stage of labour at a time when the fetus has been expelled and the fetal cotyledons separated from the maternal caruncles (Noakes et al., 2001). Success of treatment depends on the type of case, the degree of damage and contamination. The present study was aimed to highlighting the successful management of post-partum uterine prolapse in a goat.

A two years old non-descript goat of $25 \mathrm{Kg}$ body weight was presented with the history of uterine prolapse following normal kidding of 2 kids 48 hours earlier. History further revealed that this was her $2^{\text {nd }}$ pregnancy and the flock size is of 12 goats. The owner normally allowed the goat out in the morning but confined them in the pen during night. The prolapsed uterus was injured, swollen, edematous and contaminated with dung and wheat straw. The prolapsed mass had numerous bleeding points and had laceration (Fig. 1). Vaginal wall was tense, edematous, swollen, thicker and bluish pink in appearance. The goat was dull, depressed and anorectic with body temperature of $105^{\circ} \mathrm{F}$, heart rate $120 / \mathrm{min}$ and respiration rate 74 / $\mathrm{min}$.

The epidural anesthesia was achieved by infiltration of $2 \%$ lignocaine hydrochloride @ $4 \mathrm{mg} / \mathrm{Kg}$ body weight into lumbosacral space to prevent straining during replacement of prolapsed mass. After allowing 8-10 minutes for the anesthetic to take effect, sensitivity around the perineal region was assessed by pricking with a needle. The vulva and perineal region was cleaned thoroughly with soap solution. The prolapsed mass was washed thoroughly with chilled water containing potassium permagnate $(1: 1000)$ followed by flushing with metronidazole solution (Singh et al., 2011) and was lifted to the level of ischial arch and urine was removed from the urinary bladder by catheterization. Necrotic debris was removed. The animal was then placed on sternal recumbency and the two hind limbs were pulled outward. The prolapsed mass was lubricated with xylocain gel and replaced into normal position by gentle pressure. The body was first pushed forward followed by horns. Buhner suture using nylon (size 0) was placed in the vulva as a retention technique to hold the uterus in place as per procedure of Singh et al. (2017). The animal was administered with injection calcium magnesium borogluconate (Mifex®) @1 $\mathrm{mL} / \mathrm{Kg}$ body weight slow intravenous), injection dextrose normal saline (5\%) 200 $\mathrm{mL}$, intravenous, injection Oxytocin $10 \mathrm{IU}$, intramuscular on first day. Followed by injection ceftriaxone $\left(\right.$ Intacef $^{\circledR}$ ) @ $10 \mathrm{mg}$ / $\mathrm{Kg}$ body weight, intramuscular, injection 
Indian Journal of Animal Health, December, 2018

Management of post-partum uterine prolapse in a goat

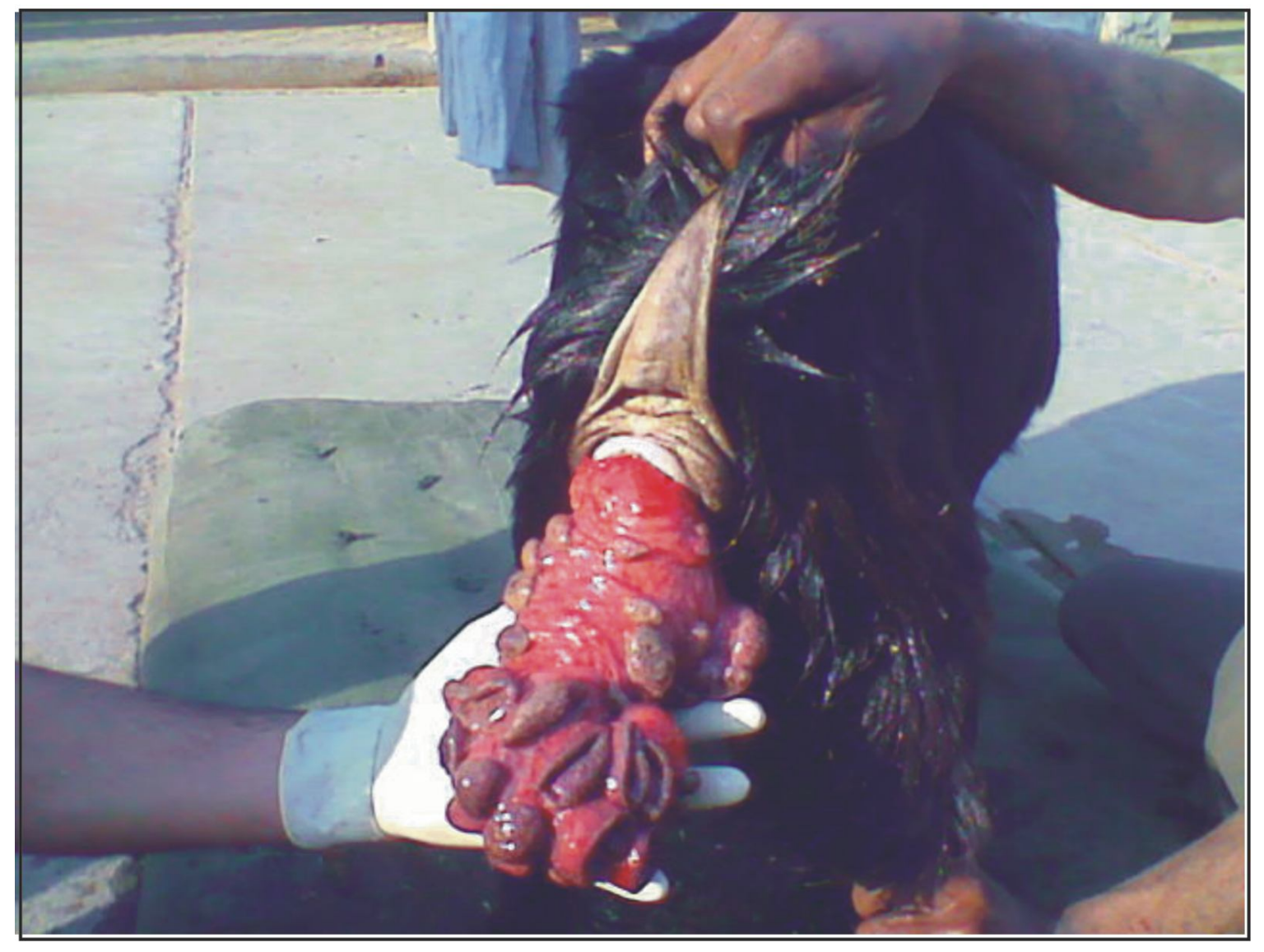

Fig. 1. Post partum uterine prolapse in a goat 
meloxicam $\left(\right.$ Melone $\left.^{\circledR}\right) @ 0.5 \mathrm{mg} / \mathrm{Kg}$ body weight, injection chlorphenramine maleate (Anistamin ${ }^{\circledR}$ ) @ $3 \mathrm{~mL}$, intramuscular, injection $\mathrm{B}_{1}, \mathrm{~B}_{6}$ and $\mathrm{B}_{12}$ (Tribivet $\left.^{\circledR}\right) @ 3 \mathrm{~mL}$, intramuscular were injected for 5 days. The owner was also advised to apply Wisprec cream on suture line for preventing infection. The animal showed recovery after 3 days and no further prolapse was reported by the owner. The Buhner suture was removed after 7 days of post management.

The etiology of uterine prolapse in domestic animals is not yet known. Hypocalcaemia may result in atony of genital organs, which could predispose for prolapse of genitalia (Pandit et al., 1982). Mineral imbalances have also been supposed to play an important role in the occurrence of genital prolapse. Injuries or stretching of birth passage at the first or subsequent parturition may predispose after parturition. Excessive traction at assisted parturition, dystocia or forceful removal of placental membrane may contribute to occurrence of prolapse (Hanie, 2006; Jackson, 2004). Hormonal imbalance during partum or post-partum may also cause prolapse of genitalia (Robert, 1971). Animals with uterine prolapse should be treated promptly. Any delay in management and treatment of such condition may lead to edema, ischemia, laceration, internal hemorrhage caused by weight of the organ which tear the mesovarium and artery (Noakes et al., 2001), prostration and shock making prognosis poor to hopeless (Pandey and
Pandey, 2003). Retention of the prolapsed mass is most important to prevent trauma to the prolapsed mass. A caudal epidural anesthesia was given to check the straining for easy repositioning of prolapsed mass and to relieve tenesmus with short acting lignocaine hydrochloride with the aim of desensitizing sensory, motor and autonomic nerves (Rai and Prabhakar, 2000). The uterine prolapse can be replaced in standing or recumbent position (Hanie. 2006). Once the uterus is replaced, the operator's hand should be inserted to the tip of both uterine horns so that remaining invagination could not initiate abdominal straining and prolapse (Fubini and Ducharme, 2006). If the uterus is completely and fully replaced all the way to the tips of the uterine horns, the prolapse is unlikely to occur (Hanie, 2006). Once the uterus is in normal position, oxytocin $10 \mathrm{IU}$ intramuscularly should be administered to increase uterine tone. Hypocalcemia that is thought to predispose prolapse of genital organs causing lack of normal tonicity of genitalia were treated with administration of parenteral calcium borogluconate. Meloxicam injection was given for rapid reduction of inflammation, pain and pyrexia. An injectable broad spectrum antibiotic was administered for 5 days after replacement of prolapsed mass to prevent secondary bacterial infection (Borobia-Belsue, 2006). So, broad spectrum antibiotic ceftriaxone was given to minimize infection which might be present due to exposure of the mass to the environment. Lignocain gel was applied on the prolapsed mass for lubrication as well 
as for anaesthetizing the prolapsed mass (Singh et al., 2011). Wachida and Kisan (2011) also advocated similar treatment by the use of lidocain solution as caudal epidural anaesthesia, Buhner suture using nylon (size 0) for retention of prolapsed mass, injection oxytocin, injection dexamethasone and broad spectrum antibiotic for successful management of uterine prolapse in doe goat.

\section{REFERENCES}

Borobia-Belsue J, 2006. Replacement of rectal prolapse in sow. Vet Rec, pp 380

Fubini SL and Ducharme GN, 2006. Surgical conditions of post-partum period. Text Book of Farm Animal Surgery, pp 333338

Hanie FA, 2006. Prolapse of the vaginal and uterus: Text Book of Large Animal Clinical Procedures for Veterinary Technicians. Elsevier, Mosby, pp 218221

Jackson PGS, 2004. Hand Book of Veterinary Obstetrics. $2^{\text {nd }}$ Edn., Elsevier Saunders, pp 209-231

Noakes DE, Parkinson TJ and England GCW, 2001. Arthur's Veterinary Reproduction and Obstetrics. Saunders, pp 333-338

Pandey G and Pandey V, 2003. A case of uterine prolapse in goat. Indian Vet Med J, 26: 378

Pandit RK, Gupta SK and Pattabirman SR,
In the present study, it was concluded that reduction, reposition and retention of prolapse mass followed by administration of calcium magnesium borogluconate, oxytocin, $5 \%$ dextrose normal saline (DNS), antibiotics, antihistaminics, antiinflamatory and multivitamins successfully managed the uterine prolapse in a goat.

1982. A clinical study of vagina and uterus in buffaloes. Indian Vet J, 59: 975-980

Rai C and Prabhakar S, 2000. Clinical effects of epidural administration of Xylazine in buffaloes having pre-partum vaginal prolapse, Indian Vet J, 77: 247-249

Roberts SJ, 1971. Veterinary Obstetrics and Genital Diseases (Theriogenology) $2^{\text {nd }}$ Edn., CBS Publisher and Distributors, Delhi, pp 233-240

Singh B, Singh KP, Singh SV, Singh JP and Singh HN, 2011. Post partum cervicovaginal prolapse in buffalo. Intas Polivet, 12(1): 32-33

Singh KP, Singh B, Singh P, Singh, RV and Singh JP, 2017. Management of post partum cervico-vaginal prolapse in a buffalo: A case report. Indian J Anim Hlth, 56(2): 303-306

Wachida N and Kisani AI, 2011. Uterine prolapse in a doe goat: A case report. Int J Anim Vet Adv, 3 (3): 135-137

Article received on 22.08.2018 and accepted for publication on 20.11.2018 